\title{
Chapter 8 Do ESL/EFL Teachers' Emotional Intelligence, Teaching Experience, Proficiency and Gender Affect their Classroom Practice? ${ }^{1}$
}

\author{
Jean-Marc Dewaele, Christina Gkonou and Sarah Mercer
}

\begin{abstract}
Emotions are a key part of language education for all stakeholders. Yet, to date, learner emotions have been studied more frequently than those of teachers. In this chapter, we argue that it is crucial to investigate teachers' management of their own emotions and examine any possible links with their classroom practices. We use the metaphor of teachers being like orchestra conductors, attuned to -and regulating- the emotions in the classroom. Using an online questionnaire, we collected quantitative feedback concerning classroom behaviours from 513 ESL/EFL teachers from around the world. Independent variables included Trait emotional intelligence (EI), years of teaching experience, general English proficiency and gender. Statistical analyses revealed that Trait EI and teaching experience were positively linked with levels of self-reported creativity, classroom management, and pedagogical skills and negatively linked with predictability. Level of English proficiency was only positively linked to selfreported creativity and gender had no effect. Reflecting on the implication of these findings suggests that training in emotional competences could improve the effectiveness of (trainee) teachers' classroom practices and, ultimately, also their professional well-being.
\end{abstract}

Keywords: Teacher emotions, Trait Emotional Intelligence, ESL/EFL teachers, teacher proficiency, gender, teaching experience

\subsection{Introduction}

All education is imbued with the emotions of both teachers and learners. As Aristotle most famously said, "educating the mind without educating the heart is no education at all". The challenge facing all educators is how best to teach with a recognition and consideration of the emotional dimensions of learning and teaching.

In the foreign language classroom, learners' emotions have been compared to those of wild horses, which in the hands of a good teacher can be harnessed fruitfully towards language learning (Dewaele 2015). The teacher acts as an attentive and encouraging \footnotetext{
3_8

Jean-Marc Dewaele $(\bowtie)$ Birkbeck, University of London, United Kingdom e-mail: j.dewaele@bbk.ac.uk Christina Gkonou ( $\square)$ University of Essex, United Kingdom e-mail: cgkono@essex.ac.uk Sarah Mercer $(\bowtie)$ University of Graz, Austria e-mail: sarah.mercer@uni-graz.at
}

${ }^{1}$ Pre-print of the chapter n J. de Dios Martínez Agudo (Ed.), Emotions in Second Language Teaching. Theory, Research and Teacher Education. Berlin: Springer, pp. 125-141. Doi: 10.1007/978-3-319-75438- 
guide, attuned to the linguistic, social and emotional needs of the students, gently steering them forward in their language learning journey acknowledging and working with the emotions in the classroom in the pursuit of learning objectives and broader educational goals. A good language teacher has to acknowledge the anxieties that may arise and how to manage these effectively (see Gkonou et al. 2017) as well as how to generate positive emotions to create engaging lessons, interest in the language per se, and learners' beliefs in their own potential to learn. Indeed, Dewaele, Witney, Saito and Dewaele (2017) found that foreign language (FL) learners' enjoyment (although not their anxiety) in the classroom was strongly related to their teacher.

A useful metaphor for the FL teacher is that of a conductor of an orchestra with junior musicians, such as Gustavo Dudamel and the Simon Bolivar Youth Orchestra that he directed to great acclaim at the BBC Proms in 2007, 2011 and 2016. The qualities of a good conductor could be conceived of as similar to that of a good teacher. According to concert artist Robert Meyer, "There are many attributes a good conductor should have: first, musicianship; second a good, clear beat; third, a good rapport with the orchestra; and fourth, a sense of personal magnetism. There are several other requisites but these are the main ones"i.

Replacing "musicianship" by "linguistic and cultural knowledge of the FL", the "clear beat" could be the clear voice and guidance, a good rapport with the students, and a sense of personal magnetism all apply to the FL classroom equally as well as to the orchestra.

Essentially, a good language teacher needs to be in a position to manage the emotional tenor of the classroom. This means not only should they be able to harness the emotions of their learners, but they should also be able to regulate their own emotions to ensure they are in the right frame of mind to create positive rapport with learners, generate enjoyment and manage any anxieties. Reflecting on how interconnected teacher and learner psychologies are (Mercer 2016), it is surprising to note how little attention is paid to the teachers themselves in language learning psychology research, especially compared to the depth and breadth of work on learners (Dewaele 2017a; Mercer et al. 2016; Mercer 2016; Mercer and Kostoulas, in press). We therefore feel that there is a need to work towards a deeper understanding of language teacher psychology including in particular how they manage the emotional complexity of the FL learning classroom for themselves and their learners.

The current study represents a small step towards filling that gap by attempting to identify some sources of individual differences (IDs) in teachers' classroom behaviour connecting their emotional intelligence to their classroom practices. Specifically, we will investigate the effect of a range of IDs on EFL and ESL teachers' self-reported classroom practices focusing on the possible links with Trait Emotional Intelligence (Trait EI; Petrides 2009), English proficiency, length of their teaching experience, and gender.

\subsection{Literature Review}

A key ability for managing emotions of oneself and others is emotional intelligence (EI), which can be thought of as a developing competence or as a level of personality trait. The concept of Trait EI emerged from the distinction between the two EI constructs (Ability EI and Trait EI; Petrides and Furnham 2000, 2001). Trait EI is 
formally defined as a constellation of emotional perceptions located at the lower levels of personality hierarchies assessed through questionnaires and rating scales (Petrides et al. 2007). Trait EI essentially concerns people's self-perceptions of their emotional abilities and their inner world. An alternative label for the same construct is trait emotional self-efficacy (ibid). The authors describe people who score high on EI as being

flexible and willing to adapt to new conditions (...) forthright, frank and willing to stand up for their rights (...) clear about their own and other people's feelings (...) capable of communicating their feelings to others (...) capable of influencing other people's feelings (...) capable of controlling their emotions (...) reflective and less likely to give in to their urges (...) capable of having fulfilling personal relationships (...) successful and self-confident (...) driven and unlikely to give up in the face of adversity (...) accomplished networkers with excellent social skills (...) capable of withstanding pressure and regulating stress (...) capable of taking someone else's perspective (...) cheerful and satisfied with their lives (...) confident and likely to 'look on the bright side' of life (ibid: 274).

Insights from general education have revealed that high levels of Trait EI in teachers have implications for their classroom management and practice. For example, empirical research has shown that highly emotionally intelligent teachers are better able to deal with the challenges of contemporary classroom life such as working with diverse heterogeneous classes, managing group dynamics or coping with increasing levels of teacher stress and burnout (see, e.g., Brackett et al. 2010; Chan 2006; Corcoran and Tormey 2012a, 2012b, 2013; Jennings and Greenberg 2009). It has also been shown that such teachers tend to design more engaging lessons aimed at promoting learners' motivation (Elias and Arnold 2006; Graziano et al. 2007; Nizielski et al. 2012) and work at reducing rates of bullying and antisocial behaviour in their classes (Gross and Levenson 1993, 1997; Richards and Gross 1999).

Within applied linguistics, research into Trait EI remains scarce, albeit with some notable exceptions. For example, Dewaele, Petrides and Furnham (2008) found that high Trait EI was linked with lower levels of communicative anxiety in the L1 and of foreign language anxiety in the L2, L3, L4 and L5 of 464 adult multilinguals. The authors suggested that the high Trait EI reflected participants' capacity to control and communicate their emotions and their ability to empathise with their interlocutors. This allowed them to gauge whether the interaction was going well, adjusting if necessary, which had the overall effect of lowering their anxiety. Low Trait EI participants, on the other hand, remained in the dark about the emotional state of their interlocutors and the success of the interaction, with little capacity to adjust if necessary, leading to increased anxiety across their languages.

With regard to FL teachers, high Trait EI among language teachers was found to be connected to stronger teacher self-efficacy (Moafian and Ghanizadeh 2009) and stronger emotion-regulation skills during teaching (Gregersen et al. 2014). Additionally, interesting findings emerged through a recent project which investigated English language teachers' emotional and social intelligence (see Gkonou and Mercer 2017; Gkonou and Mercer, in press). In particular, the quantitative findings revealed that English teachers reported high levels of Trait EI $(M=107.4$; $\min =20, \max =140)$, and that gender and length of teaching experience were significant predictors of Trait EI. The qualitative findings also showed that these highly emotionally intelligent English 
teachers drew on their teaching experience and the variety of past classroom experiences to interpret and respond to current classroom events and manage the class accordingly. Teacher expertise and the subsequent intuitive knowledge gained through their long and varied teaching experience shaped their Trait EI and were activated when called upon to take emotion-related decisions in class.

In a study based on data collected from the same participants as in the present study, Dewaele and Mercer (2017) considered variation in 513 EFL/ESL teachers' selfreported attitudes towards their students. The authors found that teachers with high levels of Trait EI had more positive attitudes towards their students and enjoyed their lively students more. An implication of this finding is that people with low levels of EI may find the teaching profession particularly challenging; however, specific training may boost trainee teachers' levels of EI (cf. Vesely et al. 2014). Another encouraging finding was that more experienced teachers had more positive attitudes towards their students although they did not explicitly enjoy working with lively students more. Because of attrition in the teaching profession, it is possible that the participants with longer experience may simply have been the "better" teachers anyway. Teachers' English proficiency also emerged as an important independent variable. More proficient teachers reported significantly more positive attitudes towards their students and also reported enjoying working with their lively students more. This was interpreted in terms of self-efficacy and linguistic in/security. Teachers with higher levels of English proficiency did not have to worry about their position as "expert" in the FL classroom and were therefore potentially more confident and optimistic. Gender turned out to be a significant variable also, with female teachers reporting significantly more positive attitudes towards their students. The authors concluded that (trainee) teachers need to be aware of their EI competences, self-efficacy, and FL proficiency, as they are likely to affect their professional well-being as well as the relationships with learners in their classrooms.

Reflecting on the review of the literature on Trait EI in applied linguistics raises some interesting questions and reveals many yet-to-be-explored areas. As such, our aims in the present study are to begin exploring by empirically examining possible interconnections among variables which have not been researched or highlighted to date and which could connect with language teacher Trait EI and their classroom practices.

\subsection{Research Questions}

The present study aims to address the following four research questions:

1) What is the effect of Trait EI on teachers' self-reported teaching practices?

2) What is the effect of years of teaching experience on self-reported teachers' teaching practices?

3) What is the effect of English proficiency on teachers' self-reported teaching practices?

4) What is the effect of gender on teachers' self-reported teaching practices?

\subsection{Method}




\subsubsection{Instruments}

Data were collected through snowball sampling, which is a form of non-probability sampling (Ness Evans and Rooney 2013). An open-access anonymous online questionnaire was used. Calls for participation were sent through emails to teachers, students, and informal contacts asking them to forward the link to colleagues. The questionnaire remained online for six months in 2016 and attracted responses from 520 mono- and multilingual ESL/EFL teachers across the world, of which 513 filled out the questionnaire completely.

Online questionnaires are ideal for collecting large amounts of data from participants from different parts of the world belonging to various age groups and language profiles (Wilson and Dewaele 2010; Dewaele, to appear). The geographical diversity boosts the ecological validity of the results, as the effects of local educational practices are averaged out. Finally, the psychometric properties of online versions of traditional questionnaires are very similar to the pen-and-paper versions (Denissen et al. 2010).

The research design and questionnaires received ethical clearance from the first author's research institution. Participants started by completing a short sociobiographical questionnaire with questions about gender, age, nationality, country of residence, language history, and numbers of years in the profession. Participants also filled out the short version of the Trait EI Questionnaire (Short Form; Petrides 2009), which contains 30 items and yields a global Trait EI score. Items include: "On the whole, I'm able to deal with stress", "Expressing my emotions with words is not a problem for me" and "Generally, I'm able to adapt to new environments". We ran a Cronbach alpha analysis on the 30 items to investigate the reliability, i.e., "the internal consistency across individual items on a data collection instrument" (Loewen and Plonsky 2016: 40). The Cronbach alpha score was .84, which can be described as good. The mean score was $4.55(\mathrm{SD}=0.6)$, with scores ranging from 2.7 to 5.9 (absolute min $=1$, absolute $\max =7$ ). Three groups were created: those within 1 standard deviation (SD) around the mean (the middle EI group: $\mathrm{n}=339$ ), those with scores more than $1 \mathrm{SD}$ above the mean (the high EI group: $\mathrm{n}=74$ ) and those with scores more than 1 SD below the mean (the low EI group: $\mathrm{n}=85$ ).

The next part of the survey consisted of the English version of the LEXTALE, a 60item lexical test developed by Lemhöfer and Broersma (2012). The authors describe LEXTALE as a "quick and practically feasible test of vocabulary knowledge for medium to highly proficient speakers of English as a second language. It consists of a simple un-speeded visual lexical decision task", which takes "on average 3.5 minutes to complete" (Lemhöfer and Broersma 2012) ) $^{\mathrm{ii}}$. The test gives a good indication of overall English proficiency. LEXTALE scores have been found to correlate highly with TOEIC test results, an established test of English proficiency (ibid). Thus, even though LEXTALE was not designed to capture general English proficiency fully, it is nevertheless a useful indicator of it (ibid). The English L1 users scored higher on the LEXTALE: $($ mean $=94.8, S D=7.6)$ than the LX users $(\text { mean }=83.5, S D=12.9)^{\mathrm{iii}}$. The difference was statistically significant $(t=12.2, p<.0001)$. Scores ranged from a minimum of 15 to the maximum possible score of 100 .

Three groups were created for proficiency: the "low" linguistic proficiency group with scores more than 1 SD below the mean $(n=94)$, the "medium" linguistic proficiency group $(n=306)$, and the "high" linguistic proficiency group $(n=53)$. 
Some participants had only just started teaching while one had been a teacher for 52 years (mean $=15$ years, $S D=10$ ). Three groups were created following the same procedure for years of experience in the teaching profession: the "low" experience group with scores more than 1 SD below the mean $(n=78)$, the "medium" experience group $(n=348)$, and the "high" experience group $(n=87)$.

\subsubsection{Participants}

A total of 513 participants ( 377 females, 131 males $^{\text {iv }}$ ) filled out the questionnaire. The mean age was 40 years $(S D=10)$. The majority of female participants is typical in webbased language questionnaires (Dewaele, to appear; Wilson and Dewaele 2010).

The largest group were British $(n=71)$, Americans $(n=40)$, followed by Ukrainians ( $n=37$ ) and smaller groups of participants with the following nationalities (in decreasing order): Greek, Azerbaijani, Argentinian, Chinese, Indian, Spanish, Turkish, Macedonian, Canadian, Austrian, Croatian, Pakistani, Belgian, Bulgarian, Egyptian, French, Polish, Portuguese, Swiss, Hungarian, Iranian, Japanese, Saudi, Slovenian, Australian, German, Brazilian, Finnish, Italian, Jordanian, Romanian, Serbian, Singaporean, South African, South Korean, Uruguayan, Irish, Israeli, Mexican, Russian, Swedish, Algerian, Angolan, Dutch, Indonesian, Libyan, Moroccan, Nigerian, Taiwanese, Thai, Japanese, Armenian, Belarusian, Bosnian, Chilean, Cuban, Czech, Ethiopian, Filipino, Iraqi, Jamaican, Kenyan, Malaysian, Montenegrin, Mozambican, Nepalese, New Zealander, Panamanian, Peruvian, Syrian, Tunisian, Turkish Cypriot, and Venezuelan.

The sample of participants consisted of 15 monolinguals, 113 bilinguals, 174 trilinguals, 104 quadrilinguals, 81 pentalinguals, 22 sextalinguals, and 4 septalinguals.

English was the most frequent L1 $(n=136)$, the remaining 376 participants had English as an LX.

A majority of participants were teaching English at university $(n=290)$, with smaller numbers teaching in secondary schools $(n=154)$, primary schools $(n=63)$, and nursery schools $(n=6)$.

The largest group of participants were working in Ukraine $(n=37)$, Greece $(n=32)$, Spain $(n=30)$, Azerbaijan $(n=25)$, Japan $(n=25)$, UK $(n=17)$ and USA $(n=17)$. The remaining participants worked in 103 different countries.

\subsubsection{Dependent Variables}

To generate a broad overview of self-reported teaching practices, data were elicited through the following general closed questions:

1) Would you describe yourself as a creative teacher? Responses included: No, A little, to some extent, yes, yes-very much so.

2) How predictable are your classes (i.e., how much do you stick to similar routines)? Possible answers included: Very predictable, predictable, it varies, not predictable, very unpredictable.

3) How would you describe yourself as an English teacher in terms of classroom management skills? Responses included: Far below average, Below average, Average, Above average, Far above average. 
4) How would you describe yourself as an English teacher in terms of pedagogical or didactic skills? Responses included: Far below average, Below average, Average, Above average, Far above average.

We operationalised teachers' teaching practices through classroom management and pedagogical skills as these represent two key competencies for teachers and teaching in general. We have also included two additional constructs, namely creativity and predictability, given that these variables yielded interesting findings in previous studies (Dewaele et al. 2017). A one-sample Kolmogorov-Smirnov test revealed that the scores on the four 5-point Likert questions were not normally distributed (all $p<.0001$ ), see also Figure 1 that shows the distribution of scores. Mean score for creativity was 3.9 $(S D=.8)$, for predictability it was $3.0(S D=.7)$, for classroom management it was 3.8 $(S D=.7)$, and for pedagogical skills it was $3.9(S D=.7)$.

Figure 1. Proportion of participants choosing a specific Likert scale score for the four questions on their classroom behavior

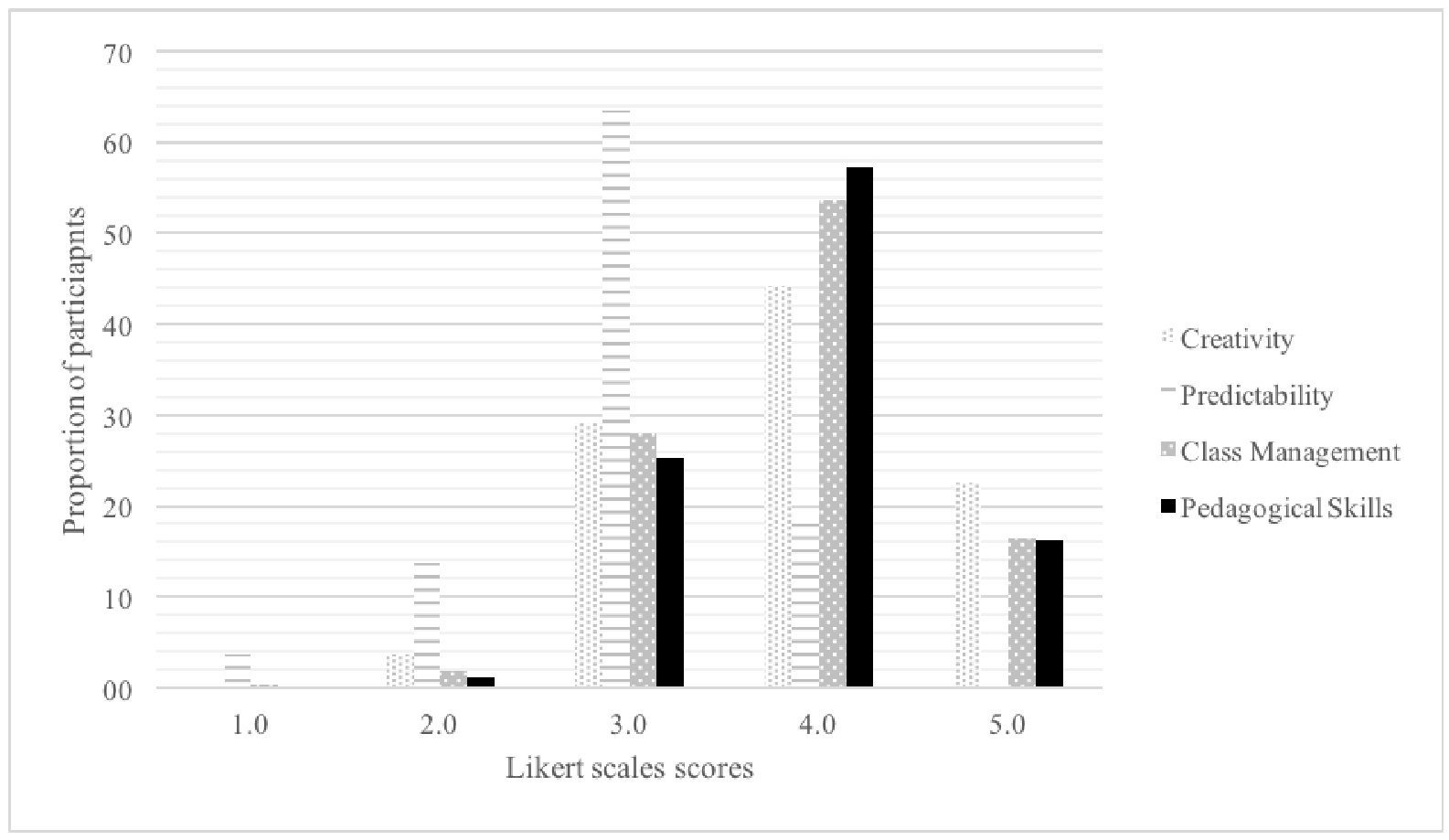

\subsubsection{Results}

Kruskal Wallis tests revealed that Trait EI had a statistically significant effect on teachers' self-reported creativity, classroom management, and pedagogical skills. It had a marginally significant effect on predictability (see Table 1). The results are visualised in Figure 2 (based on mean scores). The analyses show that increased Trait EI is linked to more creativity, better classroom management, and stronger pedagogical skills - as well as marginally lower predictability in the classroom. The differences between groups are generally largest between the medium and the high Trait EI groups. 
Table 1: Effect of Trait EI on self-reported creativity, predictability, classroom management and pedagogical skills (mean ranks)

\begin{tabular}{|c|c|c|c|c|}
\hline $\begin{array}{l}\text { Level Trait } \\
\text { EI }\end{array}$ & Creativity & Predictability & $\begin{array}{l}\text { Class } \\
\text { management }\end{array}$ & $\begin{array}{l}\text { Pedagogical } \\
\text { skills }\end{array}$ \\
\hline Low & 207 & 270 & 235 & 234 \\
\hline Medium & 246 & 250 & 241 & 240 \\
\hline High & 315 & 224 & 303 & 310 \\
\hline$C h i^{2}$ & 25.9 & 5.6 & 14.7 & 20 \\
\hline$d f$ & 2 & 2 & 2 & 2 \\
\hline$p$ & .0001 & .06 & .001 & .0001 \\
\hline
\end{tabular}

Figure 2: Effect of Trait EI on self-reported creativity, predictability, classroom management and pedagogical skills (mean scores)

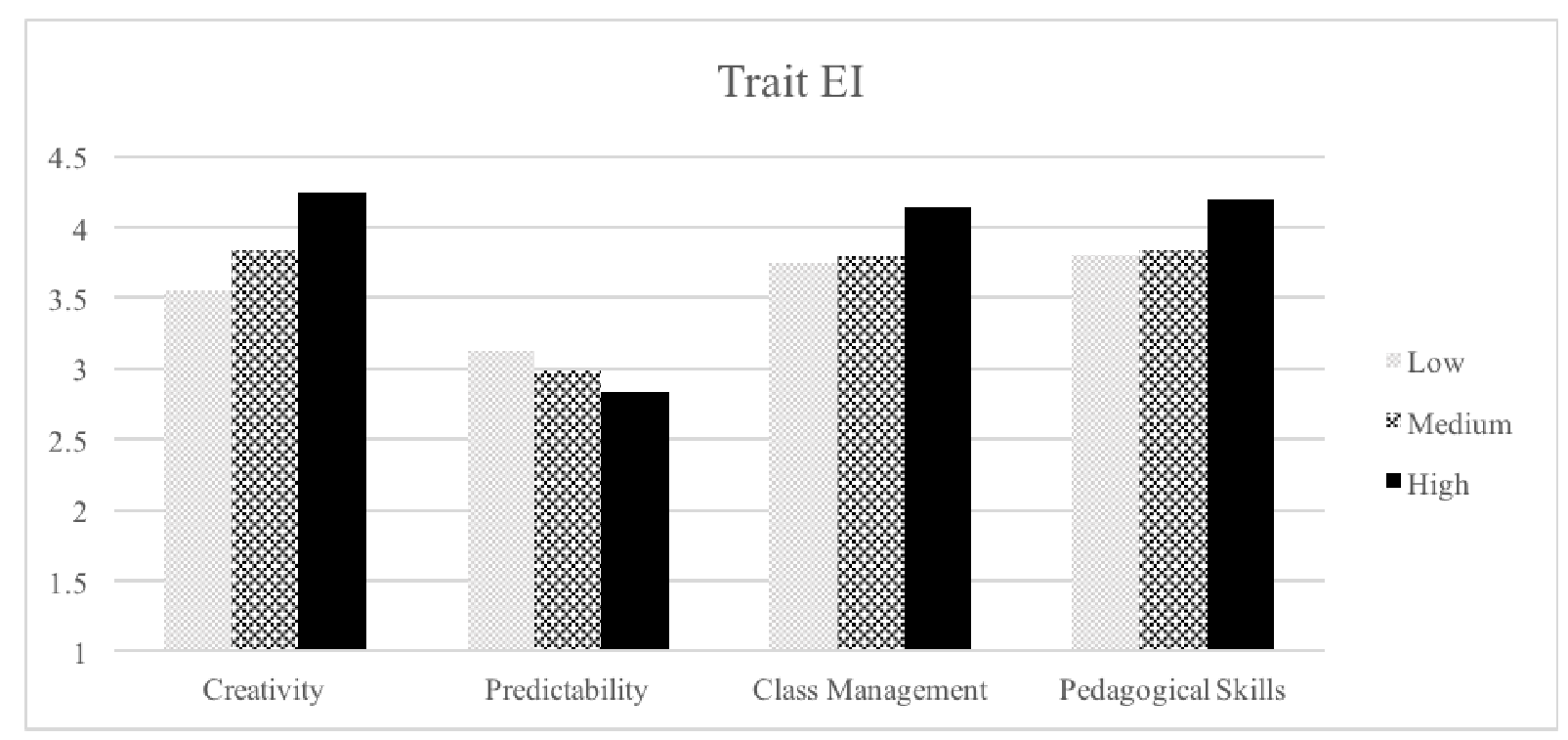

The number of years that teachers had been in the profession had a statistically significant effect on their self-reported creativity, classroom management, pedagogical skills, and it had a marginal effect on predictability (Kruskal Wallis tests). More experienced teachers scored higher on creativity, classroom management, pedagogical skills, and marginally lower on predictability (see Table 2 and Figure 3 ). 
Table 2: Effect of years of teaching experience on self-reported creativity, predictability, classroom management and pedagogical skills (mean ranks)

$\begin{array}{lllll}\text { Years } & \text { Creativity } & \text { Predictability } & \begin{array}{l}\text { Class } \\ \text { management }\end{array} & \begin{array}{l}\text { Pedagogical } \\ \text { skills }\end{array} \\ \text { Low } & 177 & 266 & 167 & 234 \\ \text { Medium } & 264 & 262 & 269 & 240 \\ \text { High } & 300 & 229 & 291 & 310 \\ & & & & \\ C h i^{2} & 35.3 & 5.2 & 43.5 & 20 \\ d f & 2 & 2 & 2 & 2 \\ p & 0.0001 & 0.075 & 0.0001 & 0.0001\end{array}$

Figure 3: Effect of years of teaching experience on self-reported creativity, predictability, classroom management and pedagogical skills (mean scores)

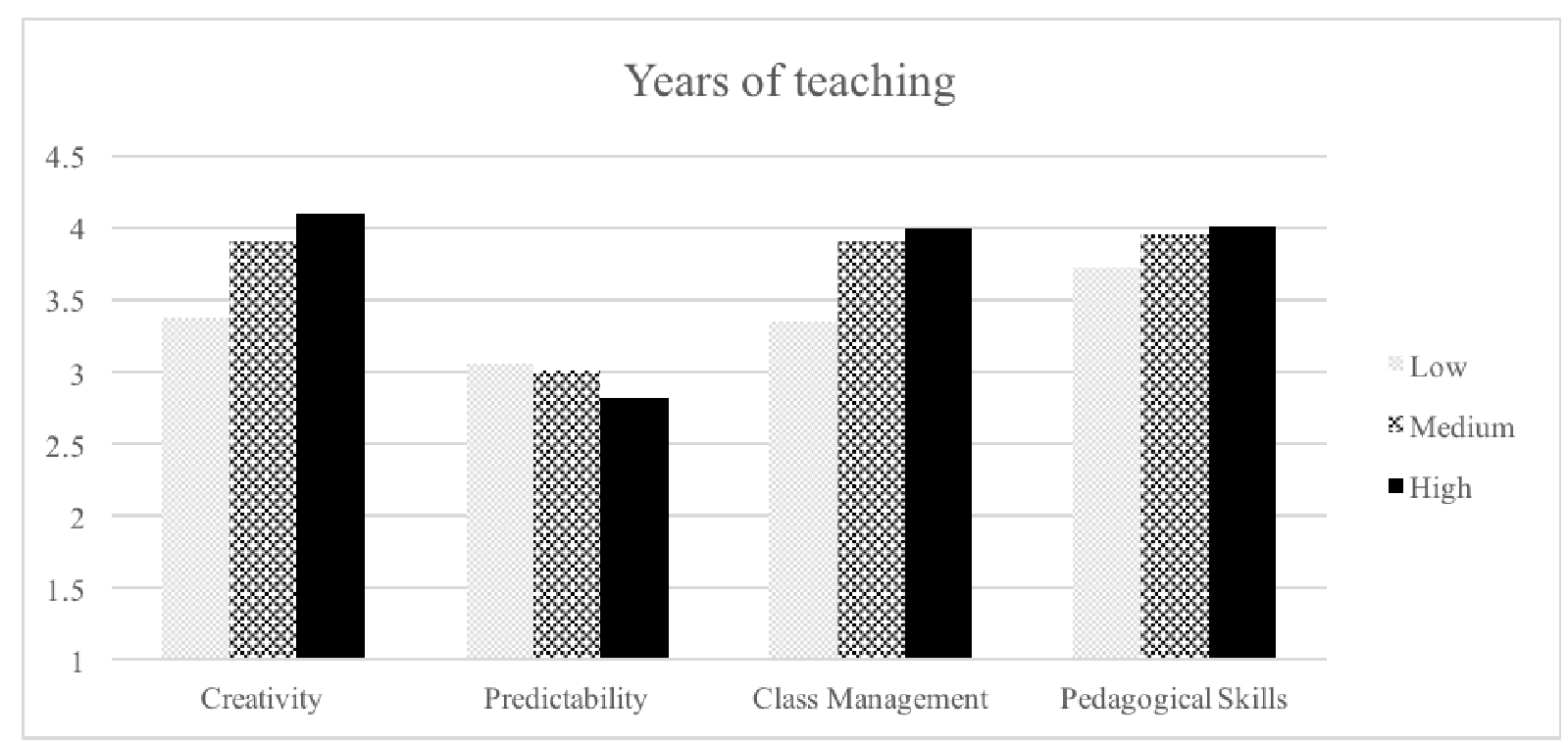

Teachers' English proficiency was linked significantly to self-reported creativity but had no effect on predictability, classroom management, and pedagogical skills (see Table 3 and Figure 4). 
Table 3: Effect of proficiency level on self-reported creativity, predictability, classroom management and pedagogical skills (mean ranks)

$\begin{array}{lllll}\text { Proficiency level } & \text { Creativity } & \text { Predictability } & \text { Class management } & \begin{array}{l}\text { Pedagogical } \\ \text { skills } \\ \text { Low }\end{array} \\ \text { Medium } & 214 & 268 & 240 & 233 \\ \text { High } & 261 & 252 & 260 & 261 \\ & 305 & 268 & 268 & 270 \\ C h i^{2} & & & & \\ d f & 15.6 & 1.6 & 2 & 4 \\ p & 2 & 2 & 2 & n s\end{array}$

Figure 4: Effect of proficiency level on self-reported creativity, predictability, classroom management and pedagogical skills (mean scores)

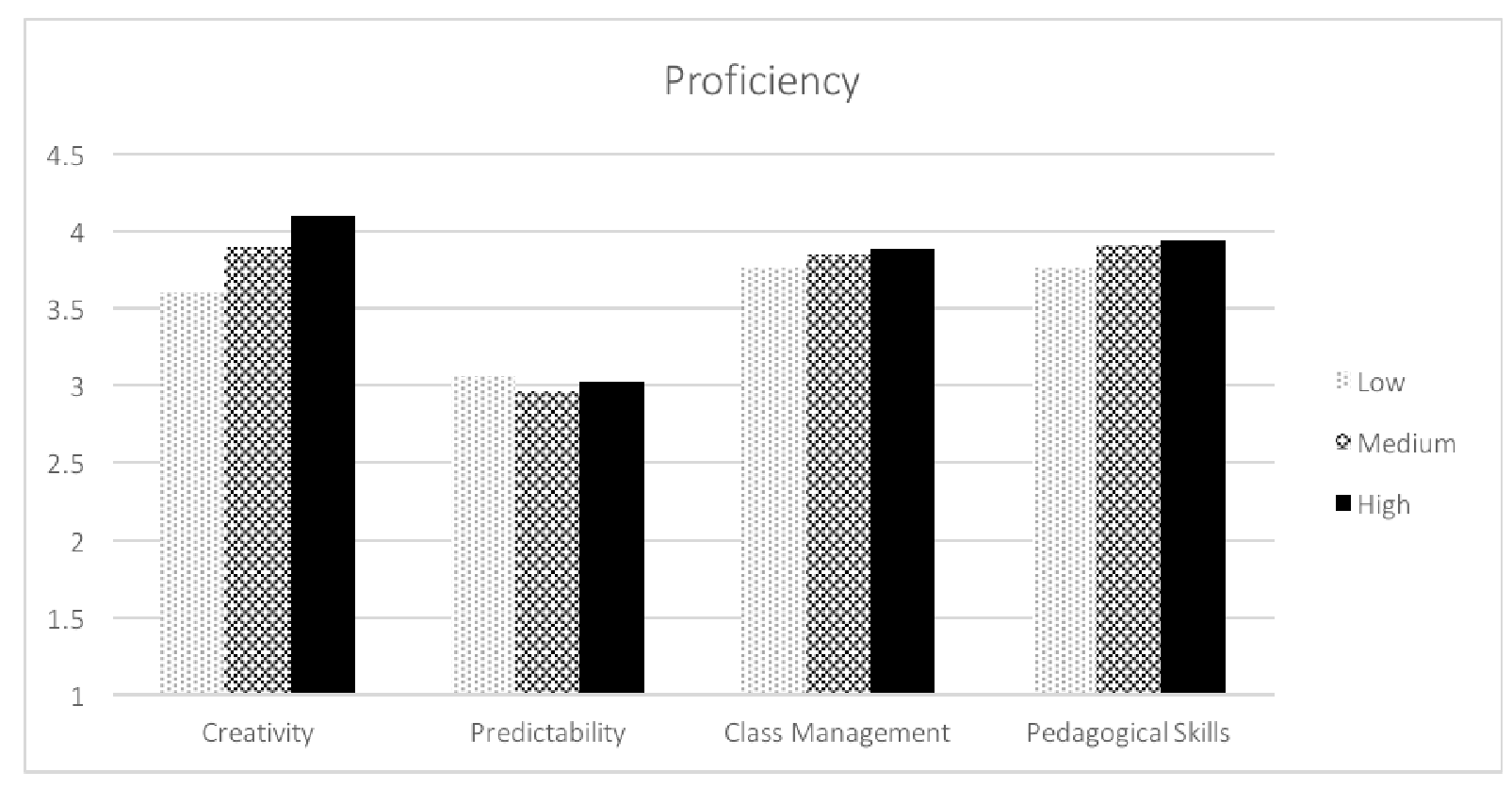

A Mann-Whitney test revealed that no statistically significant gender differences existed for self-reported creativity, predictability, classroom management, and pedagogical skills (see Table 4). 
Table 4: The effect of gender on self-reported creativity, predictability, classroom management, and pedagogical skills (mean ranks)

$\begin{array}{lllll}\text { Gender } & \text { Creativity } & \text { Predictability } & \text { Class management } & \begin{array}{l}\text { Pedagogical } \\ \text { skills }\end{array} \\ \text { Female } & 258 & 251 & 253 & 250 \\ \text { Male } & 245 & 264 & 259 & 267 \\ & & & & \\ \text { Mann-Whitney } U & 23392 & 23472 & 24116 & 23045 \\ Z & -.96 & -.98 & -.44 & -1.28 \\ p & n s & n s & n s & n s\end{array}$

\subsubsection{Discussion}

The first research question dealt with the potential effect of Trait EI on teachers' selfreported teaching practices as represented by creativity, predictability, classroom management, and pedagogical skills. The statistical analyses show a statistically significant positive effect of Trait EI on creativity, classroom management, and pedagogical skills - and a marginal negative effect on predictability in the classroom. A closer look at the means revealed that the differences were largest between the medium and the high Trait EI groups. In other words, teachers with high levels of Trait EI had higher scores than those with lower levels of Trait EI. This complements the findings in Dewaele and Mercer (2017) with the same participants showing that high levels of Trait EI were linked with more positive attitudes towards students. This reinforces our belief that having skills in the area of EI would be beneficial for teachers in respect to various aspects of classroom behaviours and teaching practices. We would reiterate our belief in the importance for teachers to have a sufficient degree of Trait EI, and/or extra training in skills linked to EI before entering the profession or early in their careers (Vesely et al. 2014). This is crucial not only for their own emotional wellbeing and ability to cope with the pressures of being a teacher (Brackett et al. 2010; Chan 2006), but also for the classroom atmosphere, learners' emotional wellbeing, and the teaching outcomes (Jennings and Greenberg 2009). Nevertheless, we need to issue a note of caution at this point. We are aware that self-reported classroom behaviour does not necessarily accurately reflect reality, and observation data by expert raters might be a valuable additional measure worth considering in future studies. The problems with the selfreport may be especially pertinent in this study, given that people with high scores on Trait EI tend to be more optimistic (Extremera et al. 2007), so they might perceive their classroom management and pedagogical skills somewhat more positively. That said, evidence from other contexts suggests that there could be links between creativity and EI (Chan 2005) and the emotional dimensions of classroom life (Corcoran and Tormey 2012a), although empirical evidence to clearly support a connection between EI and specific teaching competences remains mixed despite high expectations for such a link (Corcoran and Tormey 2013). In addition, what classifies as classroom practices is much more complex than we were able to capture in this study and further research examining specific areas of classroom practices in more detail might help create a more fine-grained picture of the possible connections between Trait EI and particular aspects of teaching competences. 
The second research question deals with the effect of years of teaching experience on teachers' self-reported creativity, predictability, classroom management, and pedagogical skills. The patterns that emerged were very similar to those of EI. Teachers who had been in the profession for longer were more creative in their classrooms, were better at managing the classroom activities and reported stronger pedagogical skills. They were also marginally more likely to introduce a degree of unpredictability in the classroom, something learners enjoy (Dewaele et al. 2017). These patterns mirror those uncovered for attitudes towards students in Dewaele and Mercer (2017). A positive interpretation of this finding is that teachers become better through a process of trial and error learning from experience and storing up a knowledge of critical experiences to draw upon in their teaching (Gkonou and Mercer 2017). It would also correspond with other studies, which suggest lower levels of EI in pre-service teachers (Corcoran and Tormey 2012b). An alternative, more neutral interpretation is that the proportion of good teachers was higher among our more experienced participants as the weaker teachers might have left the profession.

The third research question focused on the effect of ESL/EFL teachers' levels of English proficiency on their self-reported creativity, predictability, classroom management, and pedagogical skills. Proficiency was only linked to creativity. In other words, teachers with higher levels of English proficiency reported being more creative in their classroom but proficiency level was unrelated to predictability, classroom management, and pedagogical skills. The increased creativity could be linked to increased linguistic security, meaning teachers might use a wider variety of classroom activities and use more diverse sources for their teaching involving potentially different language formats and sociolects - something a teacher with lower levels of proficiency might be more reluctant to explore.

The fourth research question looked at the effect of gender on teachers' self-reported creativity, predictability, classroom management, and pedagogical skills. No difference emerged between the 377 female and the 131 male participants. A gender difference did emerge among the same participants for attitudes towards students, with female participants reporting more positive attitudes (Dewaele and Mercer 2017). Interestingly, Gkonou and Mercer (2017) found a gender difference in reported EI scores among ESL/EFL teachers, which is in line with previous research which also showed that women tend to score higher than men. Further research could explore the extent to which gender differences may exist for various aspects of classroom practices, some of which are more closely linked to emotional dimensions and some less so.

\subsection{Conclusion}

The present study attempted to provide a first answer to the crucial question about the effect of various ID factors, in particular Trait EI on ESL/EFL teachers' self-reported classroom practices. The analysis of data collected from 513 English ESL/EFL teachers from all around the world revealed that Trait EI and teaching experience were positively linked with levels of self-reported creativity, classroom management, and pedagogical skills and negatively linked with predictability. Their level of English proficiency was only positively linked to self-reported creativity. This is encouraging as it suggests that having a slightly lower level of proficiency does not preclude one from being a good teacher. Gender had no effect. It thus seems that teachers' self-reported practices in their 
classroom are linked to both psychological traits as well as their experience gathered over the years, which would fit with work by Bar-On (2000), who also suggested that EI can develop as a result of increased life experiences. Given our expectations for the importance of Trait EI in managing the emotional dimensions of language teaching for the teachers themselves as well as for their learners and the classroom climate they create, it is encouraging to reflect that training in EI can improve the performance and the wellbeing of trainee teachers (Vesely et al. 2014) as well as potentially the emotional competences of teachers at any career stage (Brackett and Katulak 2006; Nelis et al. 2009; Zins et al. 2004). Accepting that emotions are such a key part of language education, we need to further delve into teachers' management of their own emotions and those of their learners. We hope this study can add one piece of the fascinating puzzle about the EI and teaching practices of ESL/EFL language teachers across the globe.

\section{References}

Bar-On, R. (2000). Emotional and social intelligence: Insights from the Emotional Quotient Inventory (EQ-i). In R. Bar-On \& J. D. A. Parker (Eds.), Handbook of emotional intelligence (pp. 363-388). San Francisco: Jossey-Bass.

Brackett, M. A., \& Katulak, N. A. (2006). Emotional intelligence in the classroom: Skill-based training for teachers and students. In J. Ciarrochi \& J. D. Mayer (Eds.), Applying emotional intelligence: A practitioner's guide (pp. 1-27). New York: Psychology Press/Taylor \& Francis.

Brackett, M. A., Palomera, R., Mojsa-Kaja, J., Reyes, M. R., \& Salovey, P. (2010). Emotion-regulation ability, burnout, and job satisfaction among British secondaryschool teachers. Psychology in the Schools, 47(4), 406-417.

Chan, D. W. (2005). Self-Perceived Creativity, Family Hardiness, and Emotional Intelligence of Chinese Gifted Students in Hong Kong. Journal of Advanced Academics, 16(2-3), 47-56.

Chan, D. W. (2006). Emotional intelligence and components of burnout among Chinese secondary school teachers in Hong Kong. Teaching and Teacher Education, 22(8), 1042-1054.

Corcoran, R. P., \& Tormey, R. (2012a). How emotionally intelligent are pre-service teachers? Teaching and Teacher Education, 28(5), 750-759.

Corcoran, R. P., \& Tormey, R. (2012b). Assessing emotional intelligence and its impact in caring professions: The value of a mixed-methods approach in emotional intelligence work with teachers. In A. Di Fabio (Ed), Emotional intelligence: New perspectives and applications (pp. 215-238). Croatia: InTech.

Corcoran, R. P., \& Tormey, R. (2013). Does emotional intelligence predict student teachers' performance? Teaching and Teacher Education, 35, 34-42.

Denissen, J. J. A., Neumann, L., \& van Zalk, M. (2010). How the internet is changing the implementation of traditional research methods, people's daily lives, and the way in which developmental scientists conduct research. International Journal of Behavioral Development, 34(6), 564-575.

Dewaele, J.-M. (2015). On emotions in foreign language learning and use. The Language Teacher, 39(3), 13-15. 
Dewaele, J.-M. (2017a). Psychological dimensions and foreign language anxiety. In S. Loewen \& M. Sato (Eds.), The Routledge Handbook of Instructed Second Language Acquisition (pp. 433-450). London: Routledge.

Dewaele, J.-M. (2017b). Why the dichotomy 'L1 Versus LX User' is better than 'Native Versus Non-native Speaker'. Applied Linguistics doi:10.1093/applin/amw055 (online first)

Dewaele, J.-M. (to appear). Online questionnaires in applied linguistics research. In A. Phakiti, P. De Costa, L. Plonsky \& S. Starfield (Eds.), Palgrave Handbook of applied linguistics research methodology. Basingstoke: Palgrave Macmillan.

Dewaele, J.-M., \& Mercer, S. (2017). Variation in ESL/EFL teachers' attitudes towards their students. In S. Mercer \& A. Kostoulas. Language teacher psychology (pp. 178-195). Bristol: Multilingual Matters.

Dewaele, J.-M., Petrides, K. V., \& Furnham, A. (2008). Effects of trait emotional intelligence and sociobiographical variables on communicative anxiety and foreign language anxiety among adult multilinguals: A review and empirical investigation. Language Learning, 58(4), 911-960.

Dewaele, J.-M., Witney, J., Saito, K., \& Dewaele, L. (2017). Foreign language enjoyment and anxiety in the FL classroom: the effect of teacher and learner variables. Language Teaching Research. DOI: 10.1177/1362168817692161 (online first)

Elias, M. J., \& Arnold, H. (Eds.). (2006). The educator's guide to emotional intelligence and academic achievement: Social-emotional learning in the classroom. Thousand Oaks: Corwin.

Extremera, N., Durán, A., \& Rey, L. (2007). Perceived emotional intelligence and dispositional optimism-pessimism: Analyzing their role in predicting psychological adjustment among adolescents. Personality and Individual Differences, 42(6), 1069-1079.

Gkonou, C., Daubney, M., \& Dewaele, J.-M. (Eds.). (2017). New insights into language anxiety: Theory, research and educational implications. Bristol: Multilingual Matters.

Gkonou, C., \& Mercer, S. (2017). Understanding emotional and social intelligence among English language teachers. London: British Council.

Gkonou, C., \& Mercer, S. (in press). The relational beliefs and practices of highly socio-emotionally competent language teachers. In S. Mercer \& A. Kostoulas (Eds.), Teacher psychology in SLA. Bristol: Multilingual Matters.

Gkonou, C., Tatzl, D., \& Mercer, S. (Eds.). (2016). New directions in language learning psychology. Cham: Springer International Publishing.

Graziano, P. A., Reavis, R. D., Keane, S. P., \& Calkins, S. D. (2007). The role of emotion regulation and children's early academic success. Journal of School Psychology, 45(1), 3-19.

Gregersen, T., MacIntyre, P.D., Finegan, K.H., Talbot, K.R., \& Claman, S.L. (2014). Examining emotional intelligence within the context of positive psychology interventions. Studies in Second Language Learning and Teaching, 4(2), 327-353.

Gross, J. J., \& Levenson, R. W. (1993). Emotional suppression: Physiology, self-report, and expressive behavior. Journal of Personality and Social Psychology, 64(6), 970-986.

Gross, J. J., \& Levenson, R. W. (1997). Hiding feelings: The acute effects of inhibiting positive and negative emotions. Journal of Abnormal Psychology, 106(1), 95-103. 
Jennings, P. A., \& Greenberg, M. T. (2009). The prosocial classroom: Teacher social and emotional competence in relation to student and classroom outcomes. Review of Educational Research, 79(1), 491-525.

Lee, Y. L. (2011). A study on the effect of teaching innovation on learning effectiveness with learning satisfaction as a mediator. World Transactions on Engineering and Technology Education, 9(2), 92-101.

Lemhöfer, K., \& Broersma, M. (2012). Introducing LexTALE: A quick and valid Lexical Test for Advanced Learners of English. Behavior Research Methods, 44(2), 325-343.

Loewen, S., \& Plonsky, L. (2016). An A - Z of applied linguistics research methods. London - New York: Palgrave Macmillan.

Mercer, S. (2016). Seeing the world through your eyes: Empathy in language learning and teaching. In P. MacIntyre, T. Gregersen, \& S. Mercer (Eds.), Positive Psychology in SLA. Bristol: Multilingual Matters.

Mercer, S., \& Kostoulas, A. (Eds.). (in press). Teacher psychology in SLA. Bristol: Multilingual Matters.

Mercer, S., Oberdorfer, P., \& Saleem, M. (2016). Helping language teachers to thrive: Using positive psychology to promote teachers' professional well-being. In D. Gabryś-Barker, \& D. Gałajda (Eds.), Positive psychology perspectives on foreign language learning and teaching (pp. 213-229). Cham: Springer.

Moafian, F., \& Ghanizadeh, A. (2009). The relationship between Iranian EFL teachers' emotional intelligence and their self-efficacy in Language Institutes. System, 37(4), 708-718.

Nelis, D., Quoidbach, J., Mikolajczak, M., \& Hansenne, M. (2009). Increasing emotional intelligence: (How) is it possible? Personality and Individual Differences, 47(1), 36-41.

Ness Evans, A., \& Rooney, B. J. (2013). Methods in psychological research ( ${ }^{\text {rd }}$ ed.). New York: Sage Publications.

Nizielski, S., Hallum, S., Lopes, P. N., \& Schutz, A. (2012). Attention to student needs mediates the relationship between teacher emotional intelligence and student misconduct in the classroom. Journal of Psychoeducational Assessment, 30(4), 320-329.

Petrides, K. V. (2009). Psychometric properties of the Trait Emotional Intelligence Questionnaire. In C. Stough, D. H. Saklofske \& J. D. Parker (Eds.), Advances in the assessment of emotional intelligence (pp. 85-101). New York: Springer.

Petrides, K. V., \& Furnham, A. (2000). On the dimensional structure of emotional intelligence. Personality and Individual Differences, 29(2), 313-320.

Petrides, K. V., \& Furnham, A. (2001). Trait emotional intelligence: Psychometric investigation with reference to established trait taxonomies. European Journal of Personality, 15(6), 425-448.

Petrides, K. V., Pita, R., \& Kokkinaki, F. (2007). The location of trait emotional intelligence in personality factor space. British Journal of Psychology, 98(2), 273289.

Richards, J. M., \& Gross, J. J. (1999). Composure at any cost? The cognitive consequences of emotion suppression. Personality and Social Psychology Bulletin, 25(8), 1033-1044.

Vesely, A. K., Saklofske, D. H., \& Nordstokk, D. W. (2014). EI training and pre-service teacher wellbeing. Personality and Individual Differences, 65, 81-85. 
Wilson, R., \& Dewaele, J.-M. (2010). The use of web questionnaires in second language acquisition and bilingualism research. Second Language Research, 26(1), $103-123$.

Zins, J. E., Weissberg, R. P., Wang, M. C., \& Walberg, H. J. (Eds.). (2004). Building academic success on social and emotional learning: What does the research say? New York: Teachers College Press.

\section{Recommended Readings}

-Gkonou, C., \& Mercer, S. (2017). Understanding emotional and social intelligence among English language teachers. London: British Council.

This research report describes a study conducted by two of the authors to examine levels and correlates of social and emotional intelligences among EFL teachers along with the practices of a small number of case studies. It is one of only a few studies in the field of socio-emotional intelligence in the field of language education.

-Goleman, D. (1995). Emotional intelligence: Why it can matter more than IQ. New York: Bantam Books.

A popular science book but the key work that drew attention in the wider world to the concept of emotional intelligence, even though academic work had been done beforehand. It still contains many rich ideas and is worth understanding if you intend to explore the area of emotional intelligence.

-Humphrey, N. (2013). Social and emotional learning: A critical appraisal. London: Sage.

An excellent, thorough and critical examination of the field of social and emotional learning in education. Although it focuses on the learning aspects, many of the critical debates are relevant to the researching and discussions of socio-emotional competences of teachers.

-Jennings, P. A., \& Greenberg, M. T. (2009). The prosocial classroom: Teacher social and emotional competence in relation to student and classroom outcomes. Review of Educational Research, 79(1), 491-525.

In our view, one of the key papers in the field examining the social and emotional competences of teachers and proposing a model of Social Emotional Competence (SEC). It concludes with an interesting research agenda for future work in this area.

\section{Questions for Reflection and Discussion}

- What emotional competences do teachers find they draw on frequently? In what way/s do these affect their classroom practices?

- How could a longitudinal research design, which would measure Trait EI scores at regular intervals throughout a teacher's career and would also include narratives for reflection, throw new light on the phenomena under investigation? 
- How could classroom observations and stimulated-recall interviews be used to track any differences between teachers' self-reported vs. actual classroom practices and their link to Trait EI?

- How could teachers' emotional competences be boosted through training (pre- and in-service)? What areas in particular should such training focus on?

\footnotetext{
${ }^{\mathrm{i}}$ https://robertmeyer.wordpress.com/2007/04/11/what-makes-a-conductor

ii http://www.lextale.com/whatislextale.html

iii We prefer the neutral dichotomy First Language Users (L1 users) versus Foreign Language Users (LX users) rather than the value-laden "Native versus Non Native Speakers" (cf. Dewaele 2017b).

${ }^{\text {iv }}$ Five participants did not answer this question.
} 